\title{
Does Pregnancy Potentiate the Occurrence of Adverse Drug Reactions to Antiretroviral Drugs among Nigerian Women?
}

\author{
Article by Samson C Emelike \\ Senior Technical Officer, Abuja \\ E-mail: scemelike@gmail.com
}

\begin{abstract}
HIV transmission can occur from mother to child during pregnancy, delivery and breastfeeding. The use of Anti-Retroviral Drugs (ARD or ARVs) in Prevention of Mother to Child Transmission can significantly reduce this mode of transmission. The use of ARVs has been associated with occurrence of noxious effects known as Adverse Drug Reactions (ADRs). It is well known that women react more to drugs than men and some reasons proffered by some literature include hormonal differences in both sexes; but it is not known whether pregnancy can increase the chances of women reacting adversely to ARVs.

Objective: The objective of the research is to investigate whether pregnancy can potentiate the occurrence of ADRs to ARVs.

Methodology: The research employed a cross sectional Study Design on 150 HIV positive pregnant women, who were receiving ARVs at the time of study but who started ARVs before the current pregnancy. A simple Random Sampling Technique was employed in selecting the subjects. A wellstructured questionnaire was applied on the selected women to collect data.

Data Analysis: The result was analyzed in a Mcnemar's test using Statistical Package for Social Sciences to determine the strength of association between the variables pregnancy and occurrence of $A D R s$ for both the pregnant and the non-pregnant statuses of the same subjects.

Result: The result showed that pregnancy does not contribute to the occurrence of Adverse Drug Reactions to Antiretroviral drugs among HIV pregnant women.
\end{abstract}

Keywords: Pregnancy, adverse, drug, reaction, ARVs, potentiate.

\section{Introduction}

HIV infection can be transmitted from mothers to their unborn children during pregnancy, delivery and breastfeeding. It has been estimated that pregnancy, childbirth and breastfeeding account for 15$45 \%$ chances of transmission if no intervention is provided.

The use of Antiretroviral drugs (ARDs or ARVs) during pregnancy and breastfeeding significantly reduces the chances of transmission to less than $1 \%$.

The use of ARVs is associated with occurrence of Adverse Drug Reactions (ADRs). These are unwanted and noxious effects associated with the use of drugs, in this case ARVs. These effects are most times responsible for poor adherence to medication which ultimately results to poor treatment outcomes.

ADRs occur more in women than in men. This gender tilted phenomenon has been explained to be due to several reasons including the biology of the female gender, the physiology, hormonal contents and some social traits of the female entity. For instance, females react to Nevirapine more adversely than the male counterpart at the same CD4 count of say $400 \mathrm{cells} / \mathrm{ml}^{3}$ due to reasons adduced above.

Recently, the world has become ambitious to end the HIV/AIDS epidemic by the year 2030. To achieve this, it has given itself a target of ensuring that $90 \%$ of the world population living with the virus would know their status by the year 2020. It intends to place $90 \%$ of the population diagnosed with the virus on Highly Active Anti-Retroviral Therapy (HAART), and hopes to achieve maximal viral suppression in $90 \%$ of those placed on HAART. This is the 90-90-90 paradigm of HIV interventions.

This ambition is laudable; however, the second and last 90s of the target depend largely on good medication adherence to succeed. In the presence of unintended and noxious effects from ARVs, 
patients who are placed on HAART would not continue medication, and the target of maximal viral suppression could be a mirage.

This project, having taken into perspective the peculiarity of the female gender being unfavorably disposed to exhibiting ADRs, therefore seeks to investigate whether pregnancy will increase the occurrence of these unintended noxious effects or not. If it does, then pregnancy would be considered as a barrier to achieving this ambitious target of ending the HIV/AIDS epidemic in 2030.

Pregnancy is defined as absence of menses with the evidence of conception in a woman. It is a time when a woman carries an offspring in her womb. Pregnancy is associated with hormonal changes which may interfere with the way women react to ARVs.

\section{Problem statement}

Mother to child transmission (MTCT) of HIV is the highest source of new HIV infection in children below the age of 15years (WH), 2015). Nigeria is said to contribute the highest burden of mother to child transmission of HIV (Nkwo 2012). As at 2010, the estimated number of pregnant women, above 15years living with HIV in Nigeria was put at 210,000 (UNICEF, 2010).

In July 2014 in Melbourne, Australia a power consensus was reached in which United Nations and key stakeholders agreed that it was possible to end the global AIDS epidemic in 2030 (UNAIDS 2015). To achieve this, an ambitious treatment target known as 90-90-90 was set for 2020 . By this year, $90 \%$ of people living with HIV would know their serological status; and then $90 \%$ of all diagnosed cases would be receiving sustained antiretroviral treatment (ART) and $90 \%$ of all those receiving ART would have sustained viral suppression (UNAIDS 2015). These are all achievable targets. Since MTCT is the highest source of HIV infection in children, an effective Prevention of Mother to Child Transmission (PMTCT) would be required to achieve the second and third 90\% targets. Good adherence to medication is required for effective PMTCT. The occurrence of ADR is a major contributory factor to poor medication adherence. This means that ADR can produce poor PMTCT intervention outcomes. Invariably, ADR can hinder the achievement of the 90-90-90 target.

Women react more adversely to drugs than men (Miller 2001). This gender bias in toxicity has been explained based on the female physiology, hormonal differences etc. (Miller 2001). In pregnancy, there are physiological and hormonal changes which can further predispose the pregnant woman to ADR occurrence. Finding out if pregnancy can predispose or potentiate the occurrence on adverse drug reactions to antiretroviral drugs will arm the world to poise better in their quest to end the epidemic within timelines.

\section{Study justification}

The outcome of this study would have global impact, considering the contribution MTCT of HIV makes in the global HIV picture. If the result proves that pregnancy increases the chances of ADR occurring, it then means the global treatment ambition of ending the global epidemic of AIDS in 2030 would be a mirage unless some critical measures are put in place to provide alternate regimens with better tolerability profiles. This study therefore becomes handy to forewarn United Nations and key stakeholders on the likely outcomes of PMTCT intervention. This would go a long way in saving resources in terms of finance, human and time.

\section{Objectives}

The objective of this study was to investigate whether pregnancy can increase the occurrence of Adverse Drug Reactions to Antiretroviral drugs or not.

\section{Hypotheses}

$\mathbf{H}_{\mathbf{0}}$ : Pregnancy does not contribute to the occurrence of adverse drug reactions to antiretroviral drugs in HIV pregnant women

$\mathbf{H}_{\mathbf{a}}$ : pregnancy contributes to the occurrence of adverse drug reactions to antiretroviral drugs in HIV pregnant women. 


\section{Methodology}

\section{Study area and period}

Two study areas were selected. These were Federal medical center Umuahia and Abia State University Teaching Hospital, Aba both in Abia State of Nigeria. Umuahia and Aba are two major cities in the state. Umuahia is the state capital while Aba is the commercial nerve center, not just for the state alone, but also for the entire South East Nigeria. The choice of these two cities is strategic due to large number of patients that access these facilities.

\section{Study population}

The target of this research was HIV positive pregnant women who were currently receiving ARVs and must had started ART prior to the current pregnancy. The sample size was chosen arbitrarily as 150 .

\section{Study duration}

The study lasted six months between November 2016 and April 2017

\section{Sampling method}

The research employed a cross sectional Study Design on 150 HIV positive pregnant women, who were receiving ARVs at the time of study but who started ARVs before the current pregnancy. A simple Random Sampling Technique was employed in selecting the subjects. Subjects who met the inclusion criteria were randomly picked and assigned a serial identification number before administering the questionnaire. This process continued until 150 subjects were selected.

\section{Sample size}

Sample size determination was chosen arbitrarily as 150

Inclusion Criteria: Criteria used to include subjects include the following

- $\quad$ Subject must be a female gender

- She must be HIV positive

- $\quad$ Subject must be currently pregnant and taking ARVs during the study.

- $\quad$ Subject must have been on ART prior to current pregnancy

\section{Study tools}

Study tools employed in the study are one-on-one interviews, well-structured questionnaire

\section{Data collection}

The individual completed questionnaires were collated on Microsoft Excel and consolidated to present the responses of all 150 subjects. Four hospital pharmacists at the selected facilities were engaged to administer the questionnaires and their responses recorded.

Data Analysis

The data obtained is a categorical paired sample data, and it requires McNemar's test to analyze. Using SPSS, the McNemar's test was run to obtain results.

\section{Results}

The ADR responses from the 150 subjects is presented in Table $\mathbf{1}$ under figures and Tables.

The data in Table 1 was analyzed with McNemar's test in SPSS; the outputs obtained is presented in Table 2a-2c

The result showed that out of the 150 subjects interviewed, 7 subjects experienced ADR (and 147 with no ADR) before pregnancy, and 13 experienced ADR (and 137 with no ADR) during pregnancy. Further disaggregation showed that ADR occurred in 5 paired subjects both before and during pregnancy; 8 experienced ADR only during pregnancy; while 2 experienced ADR only before pregnancy. 
From the Chi-square tests above, the P-value is not statistically significant, and so we accept the null hypothesis that Pregnancy does not contribute to the occurrence of adverse drug reactions to antiretroviral drugs in HIV pregnant women.

The observations and findings of this research will be discussed under two subheadings: - findings in the absence of pregnancy and findings in pregnancy.

The age distribution of the respondents showed that $70 \%$ of the subjects were within the age range 20-29 years, while 30\% fell into the 30-39 years' age bracket. About 37\% of respondents attained a tertiary education level and $63 \%$ with secondary education level. All subjects were pregnant during the study as designed. The ages of pregnancy were distributed as $35 \%$ in $1^{\text {st }}$ trimester; $41 \%$ in $2^{\text {nd }}$ trimester while approximately $24 \%$ were in $3^{\text {rd }}$ trimester. About $47 \%$ of the subjects did not have previous pregnancy; $51 \%$ had 3 previous pregnancies while $2 \%$ had 4 previous pregnancies. Out of the 150 subjects interviewed, $17 \%$ did not have knowledge about ARVs for PMTCT during their previous pregnancies, whereas 38\% had such knowledge during their previous pregnancies. The result also shows that about $45 \%$ of subjects did not have previous pregnancies as reflected in their responses "Not applicable"

Of the 57 subjects that had knowledge about ARVs in PMTCT during their previous pregnancies, all of them knew where to access the drugs. There were 79 subjects representing about $53 \%$ of the study population that had previous pregnancies before the current pregnancies and they all accessed ARVs for PMTCT from study center.

\section{Discussion}

\section{In absence of pregnancy}

All subjects had been on ARVs before current pregnancies with $47 \%$ being less than 2 years old on treatment and $53 \%$ equal or older than 2 years on treatment. Regarding patient education on medication, $71 \%$ of subjects knew the name of the drugs while $29 \%$ did not know the names of the drugs they take.

All subjects responded they knew the drugs could cause adverse drug reactions. This looks a bit out of context. If about $17 \%$ did not know about the use of ARVs in PMTCT, how then would they have knowledge that they could cause ADRs? All subjects reported to be taking the right number of tablets at the right frequency. Majority reported to be taking the drug at night time, probably coinciding with their bedtimes. $60 \%$ reported there were no concomitant medicines while $40 \%$ reported to be taking other drugs when taking the drug. These drugs included ACT antimalarial medicines, analgesics, vitamins and antibiotics. Concomitant medicines could trigger drug-drug interactions which may confound possible ADR due to the drug alone, and so this needed to be taken care of. About $97 \%$ reported they were on diet not rich in fatty contents. Fatty foods enhance the absorption of Efavirenz thereby increasing the likelihood of causing unwanted effects. Another factor capable confounding the response was alcohol. Alcohol potentiates the CNS effect of EFV. Incidentally, all 150 subjects reported no alcohol consumption during previous pregnancies. Before getting pregnant, about $95 \%$ of subjects reported they did not experience ADR while taking the drug; and 5\% did. The duration of ADR can give a clue to its severity grading. Grade 1 usually does not last beyond 48 hours. About $43 \%$ of those reporting to have experienced ADR reported the ADR lasted less than 48 hours, $14 \%$ reported the ADR lasted between 3 to 5 days while the rest $43 \%$ reported the ADR lasted beyond 5 days. The ability of the ADR to resolve on its own also shows it is less serious in severity. About $86 \%$ that experienced ADR reported the ADRs resolved on their own without interventions, and in the remaining 14\%, intervention was required to resolve the ADR. None of the subjects was hospitalized due to ADR.

Ability of the affected individual to perform usual activity without assistance gives a clue to the severity grading. From severity grade 2 to grade 4, some form of assistance may usually be required to perform normal duty. Based on the responses provided by the subjects reporting ADR, $86 \%$ had WHO severity Grade 1 while $14 \%$ had ADR of WHO severity Grade 2.

\section{In pregnancy}

We wanted to know the onset of ADR if any, after administration of the drug. About $83 \%$ of subjects reported to be between 1 and 3 months old on treatment since the current pregnancy, while $16 \%$ was between 4 to 6 months old; and about $1 \%$ was between 7 to 9 months old on treatment. 
The proportion of subjects who knew the name of the drug during current pregnancy is $85 \%$. There seems to be an improvement over the time. Whereas, during previous pregnancy, only $71 \%$ knew the name of the drug.

All subjects reported to be aware the drug could cause ADR. This is the same result prior to pregnancy. All subjects took 1 tablet in a day. This is same result prior to pregnancy. Once a day taken at night.

All subjects reported to be taking other medicines along with the drug. In consideration of possible drug-food interactions, $30 \%$ reported to be on diet containing fatty nutrients during current pregnancy.

All subjects reported total abstinence from alcohol. In pregnancy, about $9 \%$ of subjects reported to experience ADR as against 5\% that reported ADR in the absence of pregnancy. Among all subjects that experienced ADR, the ADR lasted less than 48 hours in $3 \%$ of them, lasted for more than 5 days in $2 \%$ while in 3\%, the ADR lasted between 3 to 5 days. All the subjects that experienced ADR reported that the ADR resolved on their own without interventions. None of the subjects was admitted in hospital due to ADR. Out of 13 subjects that experienced ADR, only 1 (less than 1\%) needed assistance to perform usual routine functions.

In grading the ADRs according to WHO severity grading, $69 \%$ of those who reported ADR experienced WHO severity Grade 1,23\% experience Grade 2 while about $8 \%$ experienced Grade 3 severity ADR.

From the result of the research, the causality between pregnancy and occurrence of ADR is not very significant. However, this does not empirically conclude that pregnancy is not a risk factor to development of ADRs to ARVs. Obviously, there were few limitations namely the size of the population was small in comparison to the population of Abia State; so, it would not be safe to draw an unequivocal conclusion on the result of the research. Another limitation was that the questions required retrospective responses, in which subjects may have trouble recalling past events. From the responses, patient education on the drugs they take was not adequate. Patients should be empowered with adequate knowledge about the medicines they take

\section{Conclusions}

From the study, it was established that the ARVs for prevention of Mother to child transmission of HIV were available within the study area; subjects knew about it and they were accessible.

From the Chi-square tests above, the $\mathrm{P}$-value is greater than 0.05 indicating statistically insignificant value, and so the null hypothesis cannot be rejected. We therefore maintain that Pregnancy does not contribute to the occurrence of adverse drug reactions to antiretroviral drugs in HIV pregnant women

This topic should be further researched into, designed as a prospective study that would follow subjects over a period in the absence of pregnancy, and then followed up when pregnant to determine outcome. This will mitigate the impacts of the limitations experienced in this study.

Healthcare workers, especially Pharmacists should be encouraged to provide adequate education to patients on medicines.

\section{Figures and tables}

Table 1. Occurrence of Adverse Drug Reactions among HIV positive women receiving Antiretroviral drugs before and during pregnancy

\begin{tabular}{|c|c|c|c|c|c|c|c|c|}
\hline & \multicolumn{2}{|c|}{ Occurrence of ADR } & \multirow[b]{2}{*}{ ID } & \multicolumn{2}{|c|}{ Occurrence of ADR } & \multirow[b]{2}{*}{ ID } & \multicolumn{2}{|c|}{ Occurrence of ADR } \\
\hline ID & $\begin{array}{l}\text { Before } \\
\text { Pregnancy }\end{array}$ & $\begin{array}{l}\text { During } \\
\text { Pregnancy }\end{array}$ & & $\begin{array}{l}\text { Before } \\
\text { Pregnancy }\end{array}$ & $\begin{array}{l}\text { During } \\
\text { Pregnancy }\end{array}$ & & $\begin{array}{l}\text { Before } \\
\text { Pregnancy }\end{array}$ & $\begin{array}{l}\text { During } \\
\text { Pregnancy }\end{array}$ \\
\hline 1 & $\mathrm{No}$ & $\mathrm{No}$ & 51 & $\mathrm{No}$ & Yes & 101 & $\mathrm{No}$ & No \\
\hline 2 & No & No & 52 & No & Yes & 102 & No & No \\
\hline 3 & No & No & 53 & No & Yes & 103 & No & $\mathrm{No}$ \\
\hline 4 & No & No & 54 & No & No & 104 & No & No \\
\hline 5 & $\mathrm{No}$ & No & 55 & $\mathrm{No}$ & $\mathrm{No}$ & 105 & $\mathrm{No}$ & $\mathrm{No}$ \\
\hline 6 & No & No & 56 & No & No & 106 & No & No \\
\hline 7 & No & $\mathrm{No}$ & 57 & No & $\mathrm{No}$ & 107 & No & $\mathrm{No}$ \\
\hline 8 & No & No & 58 & No & No & 108 & No & No \\
\hline 9 & No & No & 59 & No & No & 109 & No & No \\
\hline
\end{tabular}


DOI: $10.21522 /$ TIJPH.2013.05.04.Art065

ISSN: 2520-3134

\begin{tabular}{|c|c|c|c|c|c|c|c|c|}
\hline 10 & No & No & 60 & No & No & 110 & No & No \\
\hline 11 & Yes & Yes & 61 & No & No & 111 & No & No \\
\hline 12 & Yes & Yes & 62 & No & No & 112 & No & No \\
\hline 13 & Yes & Yes & 63 & No & No & 113 & No & No \\
\hline 14 & Yes & No & 64 & No & No & 114 & No & No \\
\hline 15 & Yes & Yes & 65 & No & No & 115 & No & No \\
\hline 16 & Yes & Yes & 66 & No & No & 116 & No & No \\
\hline 17 & No & No & 67 & No & No & 117 & No & No \\
\hline 18 & No & No & 68 & No & No & 118 & No & No \\
\hline 19 & No & No & 69 & No & No & 119 & No & No \\
\hline 20 & No & Yes & 70 & No & No & 120 & No & No \\
\hline 21 & No & No & 71 & No & No & 121 & No & No \\
\hline 22 & No & No & 72 & No & No & 122 & No & No \\
\hline 23 & No & Yes & 73 & No & No & 123 & No & No \\
\hline 24 & No & No & 74 & No & No & 124 & No & No \\
\hline 25 & No & No & 75 & No & No & 125 & No & No \\
\hline 26 & No & No & 76 & No & No & 126 & No & No \\
\hline 27 & No & No & 77 & No & No & 127 & No & No \\
\hline 28 & No & No & 78 & No & No & 128 & No & No \\
\hline 29 & No & No & 79 & No & No & 129 & No & No \\
\hline 30 & No & Yes & 80 & No & No & 130 & No & No \\
\hline 31 & No & Yes & 81 & No & No & 131 & No & No \\
\hline 32 & No & No & 82 & No & No & 132 & No & No \\
\hline 33 & No & No & 83 & No & No & 133 & No & No \\
\hline 34 & No & No & 84 & No & No & 134 & No & No \\
\hline 35 & No & No & 85 & No & No & 135 & No & No \\
\hline 36 & No & No & 86 & No & No & 136 & No & No \\
\hline 37 & No & No & 87 & $\mathrm{No}$ & $\mathrm{No}$ & 137 & No & $\mathrm{No}$ \\
\hline 38 & No & Yes & 88 & No & No & 138 & No & No \\
\hline 39 & No & $\mathrm{No}$ & 89 & No & No & 139 & No & No \\
\hline 40 & No & No & 90 & No & No & 140 & No & No \\
\hline 41 & No & $\mathrm{No}$ & 91 & No & No & 141 & No & No \\
\hline 42 & No & No & 92 & No & No & 142 & No & No \\
\hline 43 & No & $\mathrm{No}$ & 93 & No & No & 143 & No & No \\
\hline 44 & Yes & No & 94 & No & No & 144 & No & No \\
\hline 45 & $\mathrm{No}$ & No & 95 & No & No & 145 & No & No \\
\hline 46 & No & No & 96 & $\mathrm{No}$ & $\mathrm{No}$ & 146 & No & No \\
\hline 47 & No & No & 97 & No & No & 147 & No & No \\
\hline 48 & No & No & 98 & No & No & 148 & No & No \\
\hline 49 & No & $\mathrm{No}$ & 99 & No & No & 149 & No & No \\
\hline 50 & No & No & 100 & No & No & 150 & No & No \\
\hline
\end{tabular}

Table 2a. Before Pregnancy * In Pregnancy Cross tabulation

\begin{tabular}{|c|c|c|c|c|c|}
\hline & & & In Pregr & & Total \\
\hline & & & No & Yes & \\
\hline & & Count & 135 & 8 & 143 \\
\hline & No & $\%$ within Before Pregnancy & $94.4 \%$ & $5.6 \%$ & $100.0 \%$ \\
\hline Refore Preonancy & & $\%$ within In Pregnancy & $98.5 \%$ & $61.5 \%$ & $95.3 \%$ \\
\hline Detore r tegilanty & & Count & 2 & 5 & 7 \\
\hline & Yes & $\%$ within Before Pregnancy & $28.6 \%$ & $71.4 \%$ & $100.0 \%$ \\
\hline & & $\%$ within In Pregnancy & $1.5 \%$ & $38.5 \%$ & $4.7 \%$ \\
\hline & & Count & 137 & 13 & 150 \\
\hline Total & & $\%$ within Before Pregnancy & $91.3 \%$ & $8.7 \%$ & $100.0 \%$ \\
\hline & & $\%$ within In Pregnancy & $100.0 \%$ & $100.0 \%$ & $100.0 \%$ \\
\hline
\end{tabular}


Table 2b. Chi-Square Tests

\begin{tabular}{|c|c|cc|}
\hline & Value & $\begin{array}{c}\text { Exact Sig. (2- } \\
\text { sided) }\end{array}$ & \\
\hline $\begin{array}{c}\text { McNemar Test } \\
\mathrm{N} \text { of Valid }\end{array}$ & 150 & $.109^{\mathrm{a}}$ & \\
Cases & & & \\
\hline
\end{tabular}

a. Binomial distribution used.

Table 2c. Risk Estimate

\begin{tabular}{|l|l|l|l|}
\hline \multirow{2}{*}{} & Value & \multicolumn{2}{|l|}{$95 \%$ Confidence Interval } \\
\cline { 3 - 4 } & & Lower & Upper \\
\hline Odds Ratio for Before Pregnancy (No / & 42.188 & 7.056 & 252.226 \\
Yes) & & & \\
For cohort In Pregnancy = No & 3.304 & 1.023 & 10.667 \\
For cohort In Pregnancy = Yes & .078 & .034 & .178 \\
N of Valid Cases & 150 & & \\
\hline
\end{tabular}

\section{References}

[1]. Adhikari et al. Drug use behavior of pregnant women in rural India (JPMA 61:381; 2011).

[2]. Agboghoroma et al: Nigerian prevention of mother to child transmission of human immunodeficiency virus program: The journey so far Journal of HIV \& Human Reproduction (Editorial): Jan-Jun 2013 • Vol 1 ・ Issue 1 [3]. American Pregnancy Association (APA). HIV/AIDS during pregnancy. Downloaded on March 6, 2016 from: http://americanpregnancy.org/pregnancy-complications/hiv-aids-during-pregnancy/

[4]. Arlene D. Bardeguez, Jane C. Lindsey, Maureen Shannon et al Adherence to Antiretrovirals among US Women during and after pregnancy Acquir Immune Defic Syndr. 2008 August 1; 48(4): 408-417. doi:10.1097/QAI.0b013e31817bbe80.

[5]. Brown, M. T., \& Bussell, J. K. (2011). Medication Adherence: WHO Cares? Mayo Clinic Proceedings, 86(4), 304-314. http://doi.org/10.4065/mcp.2010.0575

[6]. Centers for Disease Control and Prevention (CDC) HIV/AIDS-About HIV/AIDS

[7]. Daniel Vervloet; Stephen Durham (1998). Adverse reactions to drugs BMJ 1998; 316 doi: https://doi.org/10.1136/bmj.316.7143.1511 (Published 16 May 1998)

[8]. David A Lewis HIV/sexually transmitted infection epidemiology, management and control in the IUSTI Africa region: focus on sub-Saharan Africa. Sex Transm Infect 2011; 87: ii10eii13. doi:10.1136/sextrans-2011050178

[9]. Downloaded on March 4, 2016 from: http://www.cdc.gov/hiv/basics/whatishiv.html

[10]. Eluwa et al. Adverse drug reactions to antiretroviral therapy (ARVs): Incidence, type and risk factors in Nigeria BMC Clinical Pharmacology, Feb 2012. 1.36 · DOI: 10.1186/1472-6904-12-7

[11]. Grant, Philip M.; Cotter, Aoife G. Tenofovir and bone health Current Opinion in HIV \& AIDS: May 2016 Volume 11 - Issue 3 - p 326-332 doi: 10.1097/COH.0000000000000248. BONE COMPLICATIONS IN HIV: Edited by Patrick W.G. Mallon and Todd T. Brown. Downloaded from: http://journals.lww.com/cohivandaids/Citation/2016/05000/Tenofovir_and_bone_health.11.aspx

[12]. Haochu Li, Gifty Marley, Wei Ma, Chongyi Wei, Mellanye Lackey, Qingyan Ma, Francoise Renaud, Marco Vitoria, Rachel Beanland, Meg Doherty, Joseph D. Tucker (2017). The role of ARV associated adverse drug reactions in influencing adherence among HIV-infected individuals: a systematic review and qualitative metasynthesis. Journal article in AIDS and Behavior Feb 2017 ISBN: DOI:10.1007/s10461-016-1545-0

[13]. http://www.unicef.org/aids/files/Nigeria_PMTCTFactsheet_2010.pdf

[14]. I-Base. Guides, HIV, Pregnancy and women's health-Transmission during labour and delivery (intrapartum transmission). Downloaded on March 6, 2016 from: http://i-base.info/guides/pregnancy/labour

[15]. Jérôme Tourret, Gilbert Deray, Corinne Isnard-Bagnis Tenofovir Effect on the Kidneys of HIV-Infected Patients: A Double-Edged Sword? Published online before print September 19, 2013, doi: 10.1681/ASN.2012080857JASN October 2013 vol. 24 no. 10 1519-1527

[16]. Joint United Nations Program on HIV/AIDS (UNAIDS) Factsheets 2015- Global statistics 2015. Downloaded from: http://www.unaids.org/sites/default/files/media_asset/20150901_FactSheet_2015_en.pdf 
DOI: $10.21522 /$ TIJPH.2013.05.04.Art065

ISSN: $2520-3134$

[17]. Linda Morison The global epidemiology of HIV/AIDS British Medical Bulletin 2001;58: 7-18

[18]. Margaret Ann Miller. Gender-Based Differences in the Toxicity of Pharmaceuticals-The Food and Drug Administration's Perspective. International Journal of Toxicology, 20:149-152, 2001 1091-5818/01 \$12.00+.00 [19]. Marilia Santini-Oliveira, Ruth Khalili Friedman, Valdilea Gonc, alves Veloso, Cynthia Braga Cunha, José Henrique Pilotto, Luana Monteiro Spindola Marins, Esaú Custódio João, Thiago Silva Torres, Beatriz Grinsztejn. Incidence of antiretroviral adverse drug reactions in pregnant women in two referral centers for HIV prevention of mother-to-child-transmission care and research in Rio de Janeiro, Brazil B R A Z J I N F E C T D I S 20 1 4; 1 8(4):372-378

[20]. Marius Rademaker Do Women Have More Adverse Drug Reactions? American Journal of Clinical Dermatology December 2001, Volume 2, Issue 6, pp 349-351. Downloaded from: http://link.springer.com/article/10.2165/00128071-200102060-00001

[21]. Muaed Jamal Alomar Factors affecting the development of adverse drug reactions Saudi Pharmaceutical Journal (2014) 22, 83-94

[22]. Ngemu EK, Khayeka-Wandabwa C, Kweka EJ, Choge JK, Anino E, Oyoo-Okoth E Effectiveness of option B highly active antiretroviral therapy (HAART) prevention of mother-to-child transmission (PMTCT) in pregnant HIV women. BMC Res Notes. 2014 Jan 21; 7:52. doi: 10.1186/1756-0500-7-52.

[23]. P. Michael Ho; Chris L. Bryson and John S. Rumsfeld (2009). Medication Adherence. Circulation 2009; 119:3028-3035, originally published June 15, 2009. https://doi.org/10.1161/CIRCULATIONAHA.108.768986

[24]. P.O Nkwo Prevention of Mother to Child Transmission of Huma Immunodeficiency Virus: The Nigerian Perspective. Ann Med Health Sci Res. 2012 Jan-Jun; 2(1): 56-65. Doi: 104104/2141-9248.96940

[25]. Ruth E. Tuomala, David E. Shapiro, Lynne M. Mofenson, Yvonne Bryson, Mary Culnane, Michael D. Hughes, M.J. O'Sullivan, Gwendolyn Scott, Alice M. Stek, Diane Wara, Marc Bulterys, Antiretroviral Therapy during Pregnancy and the Risk of an Adverse Outcome. N Engl J Med 2002; 346:1863-1870June 13, 2002DOI: 10.1056/NEJMoa991159 Downloaded from: http://www.nejm.org/doi/full/10.1056/NEJMoa991159

[26]. The US Department of Health \& Human Services. About HIV \& AIDS: How is HIV transmitted? Downloaded on March 5, 2016 from: https://www.aids.gov/hiv-aids-basics/hiv-aids-101/how-you-get-hiv-aids/

[27]. Thorne C, Patel D, Newell ML Increased risk of adverse pregnancy outcomes in HIV-infected women treated with highly active antiretroviral therapy in Europe. AIDS 2004; 18:2337-2339. Downloaded from: http://europepmc.org/abstract/med/15577551

[28]. UNICEF, Nigeria PMTCT Factsheet, 2010. Downloaded on March 2, 2016 from:

[29]. Victor O. Dinwoke, Charles I. Okafor: Prevention of Mother To Child Transmission (PMTCT) Of Human Immunodeficiency Virus (HIV): Perceptions and Practice Of Antenatal Clients In Nnewi, South-East Nigeria. Trop J Obstet Gynaecol, 30 (2), August 2013

[30]. WHO. International drug monitoring: the role of National Centres. Tech Rep Ser WHO 1972, no 498

[31]. World Health Organization (WHO) July 2015: HIV/AIDS Mother-to-child transmission of HIV. Downloaded on February 24, 2016 from: http://www.who.int/hiv/topics/mtct/en/ 